\title{
PRELIMINARY EVALUATION OF THE USE VALUE OF JUMPING HORSES BASED ON THEIR RESULTS ACHIEVED IN GRAND PRIX COMPETITIONS*
}

\author{
Tomasz Próchniak*, Iwona Rozempolska-Rucińska, Grzegorz Zięba \\ Department of Biological Bases of Animal Production, University of Life Sciences in Lublin, \\ Akademicka 13, 20-950 Lublin, Poland \\ •Corresponding author: tomasz-prochniak@wp.pl
}

\begin{abstract}
The aim of the work was preliminary evaluation of predispositions of Polish racehorses to sports. The tests covered 273 horses taking part in CC class and CC1 class competitions in the finals of the big tour. The probability of achieving the best result in the competitions depending on the horse breed was evaluated using multivariate analysis of variance. With the use of Spearman's rank correlations, the initial correspondence between the horse's rank in breeders' ranking and the ranking based on sport results was defined. It was stated that horses starting in Grand Prix competitions represented only $6.85 \%$ of all horses registered in the Polish Equestrian Federation. In the group, foreign breeds were predominant. The proportion of native breeds was marginal. The lack of a significant influence of the race on differentiation of sports results of horses proves that the best specimens were chosen within individual races. The preliminary results revealed lack of rank agreement between the evaluation of the breeding value and sports achievements of an individual. This suggests the necessity of performing broader analyses covering different aspects.
\end{abstract}

Key words: horses, horse-jumping, use value, breeding value, performance test

Show jumping is the most popular horse riding discipline. Its development is influenced by the effectiveness of breeding and a number of environmental factors, which allow genetic exposition of horse's abilities (Gómez et al., 2006). The evaluation of the use and breeding values is broadly debated. Due to the comprehensibility of the term "vivaciousness", attempts are constantly made to define a universal model of evaluating horses' genetic predispositions for "Interstallion" sports use (Koenen, 2002; Ruhlmann et al., 2009). The problem has been dealt with in a number of foreign research projects (Koenen and Aldridge, 2002; Langlois and Blouin, 2004; Lührs-Behnke et al., 2002; Viklund et al., 2011). On the other hand, in Poland there has not been any research verifying the effectiveness of individual stages of breeding. The breeding value of stallions in Poland is assessed on the basis of perform-

\footnotetext{
*Work financed from statutory activity.
} 
ance tests (100-day test) in Training Centres or on the basis of the results of Polish Young Horse Show Jumping Championships. Scientists, breeders, and users differ in their opinions about the efficiency of each variant of use value assessment, and consequently their breeding value. The underdeveloped system of evaluation forces riders and trainers to use foreign breeds whose estimated sports predispositions are more reliable (Ruhlmann et al., 2009; Viklund et al., 2011). The most fundamental method of verifying the effects of horse breeding is the analysis of the sports results that their offspring achieve (Wallin et al., 2003) in a given equestrian discipline. The results of horse riding competitions provide an important aspect of use value assessment and they are taken into account when breeders make their decisions on the choice of a sire.

At the same time, a decrease in the headage of native breeds (Janczarek and Próchniak, 2010) and their attendance in the most difficult classes of competitions is observed. These facts justify the need for a thorough analysis of the topic that is aimed at taking steps to make Polish horse breeds competitive in the market.

The aim of this work was to conduct a preliminary evaluation of sports predispositions in native bred horses in comparison to foreign breeds and to define the efficiency of horse breeding in Poland.

\section{Material and methods}

The research involved 273 horses of native and foreign breeds which competed in 30 competitions of Grand Prix finals with obstacle height $140 \mathrm{~cm}$ (CC class) and $145 \mathrm{~cm}$ (CC1 class) at all national show jumping ( $\left.\mathrm{ZO}^{*}\right)$ single-star, two-star ( $\left.\mathrm{ZO} * *\right)$, and three-star $\left(\mathrm{ZO}^{* * *}\right)$ competitions and national competitions with participation of foreign riders (CSN) in 2012. In total, 774 entries of horse-rider pairs were obtained. The competition against the clock with jump-off and the so-called "winning round", where rider-horse pairs qualified together were considered as one due to the similar system of scoring. Competitions over two rounds were analysed separately as their results consisted of points obtained in two rounds in the courses with different numbers of obstacles and a different route.

With the use of multivariate analysis of variance (SAS 9.3), the probability of a clear round ( 0 penalty points) depending on the course was determined. The model takes into account the fixed effect of breed, age, sex, competition class, the random effect of the rider, and the regression of height at withers. With the use of Spearman's rank correlations, the preliminary correspondence between horse's rank in BLUP evaluation (published officially on the Polish Horse Breeders Association website) and the ranking was defined on the basis of Grand Prix competition results and rank correlations between the results of the basic round and the jump-off and the results of the first and second rounds. With the use of the MIXED procedure (SAS 9.3), the authors calculated the repeatability of results obtained by horses in the analysed competitions. The models included the following features: the fixed effect of breed, age, sex, competition class, and the random effect of the rider. Standard errors of 
repeatability were estimated with the delta method (Lynch and Walsh, 1998). The analyses involved 9 groups of purebred horse breeds: Polish breeds (Polish Noble Half-Bred Horse - pksp, Małopolski Horse - m, Wielkopolski Horse - wlkp), Dutch (Dutch Warmblood - kwpn, Dutch Warmblood Saddle Horse - nrps), Zangersheide, Selle Français, Holsteiner, Hanoverian, Westphalian, and other German breeds. The tenth group ("other") was made of individuals with the number of starts under 20 (Table 2). The percentage of horses from each age group was also determined (Table 3).

Table 1. Distribution of the number of analysed starts, depending on the competition level, class and season: indoor competitions $(\mathrm{H})$, outdoor competitions $(\mathrm{O})$

\begin{tabular}{|c|c|c|c|c|c|c|c|c|c|c|}
\hline \multirow{3}{*}{ Competition } & \multirow{3}{*}{ Class } & \multicolumn{8}{|c|}{ Competition rank } & \multirow{3}{*}{ Sum } \\
\hline & & \multicolumn{2}{|c|}{$\mathrm{ZO}^{*}$} & \multicolumn{2}{|c|}{$\mathrm{ZO} * *$} & \multicolumn{2}{|c|}{$\mathrm{ZO} * * *$} & \multicolumn{2}{|c|}{$\mathrm{CSN}$} & \\
\hline & & $\mathrm{H}$ & $\mathrm{O}$ & $\mathrm{H}$ & $\mathrm{O}$ & $\mathrm{H}$ & $\mathrm{O}$ & $\mathrm{H}$ & $\mathrm{O}$ & \\
\hline \multirow{2}{*}{$\begin{array}{l}\text { Competition against the clock } \\
\text { with jump-off and a winning } \\
\text { round }\end{array}$} & $\mathrm{CC}$ & - & 29 & - & - & - & - & - & 32 & 577 \\
\hline & $\mathrm{CC} 1$ & - & - & 143 & 69 & 52 & 43 & 23 & 186 & \\
\hline \multirow[t]{2}{*}{ Competition over two rounds } & $\mathrm{CC}$ & - & 21 & - & - & - & - & - & 51 & 197 \\
\hline & $\mathrm{CC} 1$ & - & - & - & 32 & - & - & - & 93 & \\
\hline \multicolumn{2}{|l|}{ Total } & \multicolumn{2}{|c|}{50} & \multicolumn{2}{|c|}{244} & \multicolumn{2}{|c|}{95} & \multicolumn{2}{|c|}{385} & 774 \\
\hline
\end{tabular}

Table 2. The distribution of starts in each group of horses

\begin{tabular}{lcc}
\hline \multicolumn{1}{c|}{ Breed } & No. of starts & $\%$ \\
\hline Polish (pksp, m, wlkp)* & 228 & 29.92 \\
Dutch (kwpn, nrps)** & 154 & 20.21 \\
Oldenburger (old) & 84 & 11.02 \\
Holsteiner (hol) & 70 & 9.19 \\
Hanoverian (han) & 57 & 7.48 \\
Westphalian (westf) & 35 & 4.59 \\
Zangersheide (z) & 27 & 3.54 \\
Selle Français (sf) & 22 & 2.89 \\
Other German & 27 & 3.53 \\
Other & 58 & 7.61 \\
\hline
\end{tabular}

* pksp - Polish Noble Half-Bred Horse, m - Małopolski Horse, wlkp - Wielkopolski Horse.

** kwpn - Dutch Warmblood Horse, nrps - Dutch Warmblood Saddle Horse.

Table 3. The distribution of horses' starts with regard to horse age

\begin{tabular}{lcccc}
\hline Horse's age & \% of starts & Horse age & \% of starts \\
\hline 7 & 6.19 & 13 & 4.61 \\
8 & 23.72 & 14 & 1.32 \\
9 & 23.85 & 15 & 1.32 \\
10 & 14.62 & 16 & 0.53 \\
11 & 15.68 & 17 & 0.13 \\
12 & 7.91 & 19 & 0.13 \\
\hline
\end{tabular}




\section{Results}

The analyses showed no significant influence of the breed, age, or rider on the results achieved by horses.

The probability of a clear ride in the competition was significantly different in the cases of competitions against the clock and the competitions with the "winning round" only for the group of Polish horses (0.25) and those characterised as "other" $(0.05)$ as well as between the group "other" and "Selle Français" (0.44). In the case of two-round competitions, a higher probability of a clear round was recorded for Hanoverian horses (0.61) against the Holsteiners (0.25) (Table 4).

Table 4. Probability of achieving the best result in a competition ( 0 penalty points) by horses from each breed group

\begin{tabular}{|c|c|c|c|c|}
\hline \multirow[t]{2}{*}{ Breed } & \multicolumn{2}{|c|}{$\begin{array}{l}\text { Competition against the clock with jump-off } \\
\text { and a winning round }\end{array}$} & \multicolumn{2}{|c|}{ Two round } \\
\hline & $1 \mathrm{sm}$ & se & $1 \mathrm{sm}$ & se \\
\hline Hanoverian & 0.13 & 0.10 & $0.61 \mathrm{a}$ & 0.24 \\
\hline Holsteiner & 0.13 & 0.09 & $0.25 \mathrm{~b}$ & 0.16 \\
\hline Oldenburger & 0.19 & 0.08 & 0.25 & 0.19 \\
\hline Selle Français & $0.44 \mathrm{a}$ & 0.18 & - & - \\
\hline Westphalian & 0.34 & 0.17 & 0 & 0.31 \\
\hline Zangersheide & 0.36 & 0.16 & 0.37 & 0.22 \\
\hline Other German & 0.30 & 0.15 & - & - \\
\hline Dutch & 0.19 & 0.07 & 0.04 & 0.17 \\
\hline Polish & $0.28 \mathrm{a}$ & 0.07 & 0.25 & 0.14 \\
\hline Other & $0.05 \mathrm{~b}$ & 0.10 & 0.41 & 0.24 \\
\hline
\end{tabular}

lsm - least squares mean, se - standard error.

Breed groups marked with different letters differ significantly for $\mathrm{P} \leq 0.05$.

Breed groups without marks do not differ between one another.

It was shown that although the native breeds constituted the most numerous group, their share in starts was only $29.92 \%$. Among the foreign breeds, the most numerous ones were Dutch (20.21\%) and German horses: Oldenburger $(11.02 \%)$, Holsteiner (9.09\%), and Hanoverian (7.45\%) (Table 2).

There was no correlation between the BLUP ranking, based on the evaluation in training centres, and horses' sports results (Table 6). The highest agreement was noted for the BLUP index and the results of jump-off (0.44). In other cases, the correlation was negligible.

\section{Discussion}

The lack of the effect of the breed on the final result coincides with research results obtained by other authors who deal with similar investigations (Gómez et al., 2006). However, the lack of such results in the case of the other factors can be 
justified by the fact that the best rider-horse pairs competing in the most difficult competitions were selected. They underwent all stages of training and met all the requirements imposed by the Polish Equestrian Federation on admission to the Big Round competition. The results obtained by Gomez (2006) were focused on lower rank competitions, in which the level of horses' and riders' training is lower.

Justifying such uncharacteristic differences in the probability of a clear round for individual groups of horses, one should consider the fact that among all the horses in a given breed there is a proportion of individuals predisposed to compete in equestrian competitions and achieve satisfactory results. In the case of specialised western breeds, a significant proportion of the population is predisposed to sport, whereas, in other breeds only a small number of individuals are able to meet the requirements they face in the tracks. The qualification of horses to the Big Round is a selection process, thus the analysis of the percentage of horses representing individual breeds in the above-mentioned competitions allows verification and initial evaluation of their sports predispositions (Olsson and Philipsson, 1992).

Table 5. The origin of pksp breed horses competing in Grand Prix competitions with regard to ancestors' breeds

\begin{tabular}{l|c|c|c|c}
\hline \multicolumn{1}{c|}{ Breed } & Father & $\begin{array}{c}\text { Father's } \\
\text { father }\end{array}$ & Mother & $\begin{array}{c}\text { Father's } \\
\text { mother }\end{array}$ \\
\hline Polish breeds (pksp, m, wlkp)* & 29.41 & 5.88 & 76.47 & 23.53 \\
German breeds & 41.18 & 52.94 & 10.29 & 45.59 \\
French breeds & 2.94 & 17.65 & - & 4.41 \\
Belgian and Dutch breeds & 26.47 & 20.59 & 1.47 & 13.24 \\
Other & - & - & 10.29 & 8.82 \\
\hline
\end{tabular}

* pksp - Polish Noble Half-Bred Horse, m - Małopolski Horse, wlkp - Wielkopolski Horse.

Table 6. Spearman rank correlation between the BLUP rank and sports results

\begin{tabular}{l|c|c}
\hline \multicolumn{1}{c|}{ Ranking } & & rs \\
\hline Competition against the clock & 35 & -0.27 \\
Jump-off & 11 & 0.44 \\
1st round & 20 & -0.05 \\
2nd round & 13 & -0.05 \\
Ranking in competition & 74 & $0.22^{*}$ \\
\hline
\end{tabular}

* significant for $\mathrm{P} \leq 0.05$.

Although the group of Polish horses was the most numerous (29.92\% of starts), a drastic decrease in its participation was observed, with a simultaneous increase in foreign horses' attendance: Dutch, mainly kwpn (20.21\% of starts) and German, mainly the Oldenburger (11.02\% of starts), Holsteiner (9.09\% of starts), and Hanoverian breeds ( $7.45 \%$ of starts), in comparison to national competitions in the $1980 \mathrm{~s}$ (Sasimowski and Pietrzak, 1983) when virtually only Polish bred horses participated. The attendance of Małopolski and Wielkopolski breeds was merely 2\%. A greater concern is the fact that the access to competitions is easier for these horses and that numerous steps are taken to promote conservation of breeds, mainly in a form of 
a genetic resources conservation programme (Janczarek and Próchniak, 2010). It may be anticipated that multidirectional selection of native horses contributes to the situation in which they are not fully predisposed to the show-jumping disciplines.

Polish Noble Half-Bred Horses (Table 5) were characterised by a high number of foreign ancestors (primarily from father's side), which additionally implies an increasing role of foreign breeders in Polish equestrian sports. The above-mentioned facts prove the trend of suppressing Polish breeds from equestrian disciplines by the foreign ones and a situation where riders and trainers prefer foreign bred horses, selected for sports gameness.

The analysis did not reveal any clear relations between the results achieved by horses in basic rounds or jump-off and the results from the first and second round. This is justified by the specificity of individual competitions in which riders take risks in the jump-off and the second round to obtain a satisfactory timing, even at the cost of making a mistake with an obstacle. Such a situation disrupts the real use value of the individual, just like other accidental factors (e.g. insignificant exceeding of the time limit, rider's faults), which do not negate the genetic potential of the horse. The biological background of such features as "precision" and "speed" cannot be neglected. Horses that are characterised by precision in running the course are particularly sensitive to any stimuli from physical contact with obstacle bars. This is a desirable feature and a condition of a clear course in the basic and the first round of the competition. In the jump-off and the second round, the horse's rank is determined by the time it runs the course, which depends on organism function and good quality of canter (Clayton and Barlow, 1991). Yet, the most significant factor determining sports successes is the precision of running the course, which is the most fundamental element influencing the final rank of the horse in the competition. This feature should be emphasised most intensively while evaluating the breeding value.

The lack of a correlation between the BLUP index and horses' sports results should be considered as a signal concerning the problem of discrepancy between the evaluation in training centres and the real use value of an individual horse. It is surprising that out of the 273 horses competing in such a prestigious event, as few as 9\% had been assessed in Training Centres and obtained BLUP evaluation. These two elements imply that the system of evaluating horses' breeding value, and the methods of use value estimation in particular, should be reconsidered.

Using sports results as a source of evaluating breeding values of horses is difficult due to low repeatability of sports results for a given group of horses, which was a mere $\mathrm{r}^{2}=0.19$ (se=0.03) for the examined group. This proves a significant influence of environmental conditions on the results obtained by horses, and supports the need to search for the features with lower environmental variance in the total changeability of a feature.

Due to the fact that the tests on foreign breeds proved the efficiency of the BLUP method (Wallin et al., 2003), it seems justified to make a fundamental analysis of the topic in order to prove the correctness of the national breeding strategy. The German system of evaluation (bringing satisfactory results) is based on training centre evaluation and the results of equestrian competitions in a given discipline (Koenen, 2002; 
Lührs-Behnke et al., 2002), as well as information about ancestors', relatives', and offspring's breed values (Wikström et al., 2005).

Another factor determining the correctness of breeding value evaluation is horse's age, which allows genuine evaluation of its sports predispositions. The age limits for horses competing in $\mathrm{CC}$ and $\mathrm{CC} 1$ classes (7 years) are defined by the regulations of the Polish Equestrian Federation; however, as shown in Table 4, the most numerous group included 8-year-olds $(23.72 \%)$ and 9 -year-olds $(23.85 \%)$. It can be assumed that at this age most horses are prepared for physical and mental effort involved in competitions of this type. On the one hand, the evaluation of younger horses may be erroneous; on the other hand, the results of the most difficult competitions generate the most reliable image of the use value of an individual horse.

The observed situation of lowering attendance of Polish horses in highest-rank competitions proves the necessity of reconsidering the problem. The low number of horses covered by breeding value assessment and the disproportions between BLUP evaluation and sports results suggest that it is necessary to modify the criteria of breeding value assessment by adapting them to the requirements faced by sports horses. The most important problem is the selection of features that will serve as a selection criterion, which is difficult due to the low level of repeatability of sports results and the fact the horses are usually over 8 years old. One should emphasise the need to modify the previous evaluation, whose new form can constitute valuable guidance for Polish horse breeders and users.

It can be concluded that, regrettably, the importance of foreign breeding in the national equestrian sports is on the increase through a substantial proportion of foreign ancestors in the breeds of the Polish noble half-bred horse. The discrepancy between the BLUP rank and horses' sports achievements should be regarded as a signal indicating a problem in evaluation of the use and breeding value of horses in Poland. Simultaneously, the low repeatability of results achieved by horses in sports competitions may limit the use of this source of information in estimation of the breeding value.

\section{References}

Clayt o n H.M., B a r low D.A. (1991). Stride characteristics of four Grand Prix jumping horses. Equine Exercise Physiol., 3: 151-157.

Gó m e z M.D., C e rvantes I., B a r to lo mé E., Molina A., Va l e r a M. (2006). Genetic evaluation of show jumping performances in young Spanish sport horse breed. Proc. 57th Annual Meeting of the EAAP, Antalya, Wageningen, pp. 17-20.

J a n c zarek I., Pró chni a k T. (2010). Malopolski horse breeding development in the light of its changes in the Lublin region. Annales UMCS, XXVIII: 25-36.

K o e n e n E.P.C. (2002). The Interstallion questionnaire: a valuable information source for sport horse breeders. Proc. WBFSH seminar, Budapest, Hungary, 5.11.2002, pp. 1-2.

Ko e nen E.P.C., A ldridge L.I. (2002). Testing and genetic evaluation of sport horses in an international perspective. Proc. 7th World Congr. Genet. Appl. Livest. Prod., Dublin, Ireland, 19-23.07.2002, pp. 1-5.

L a nglo is B., B lou in C. (2004). Practical efficiency of breeding value estimations based on annual earnings of horses for jumping, trotting, and galloping races in France. Livest. Prod. Sci, 87: 99-107. 
Lührs-Behnke H., Röhe R., Kalm E. (2002). Estimation of genetic parameters for traits used in the integrated breeding evaluation of German warmblood-horses. Proc. 53rd Ann. Meet. of European Ass. for Animal Prod., Cairo, Egypt, 1-4.09.2002, pp. 1-4.

Ly n ch M., Wa ls h B. (1998). Genetics and Analysis of Quantitative Traits. Sinauer Associates, Inc, Sunderland.

Ols s o n L., Phil i p s s o n J. (1992). Relationship between field test for Warmblood horses as fouryear-olds and later competition performance. Proc. 43rd Annual Meeting of the European Association of Animal Production, Madrid, Spain, 14-17.09.1992, 7 pp.

Ruhlmann C., Bruns E., Fraehr E., Philipsson J., Janssens S., Quinn K., Ric ard A. (2009). Genetic connectedness between seven European countries for performance in jumping competitions of warmblood riding horses. Livest. Sci., 120: 75-86.

S a s i mowski E., Pietrzak S. (1983). Conditions for evaluation of riding horses based on the results of official jumping competitions vs. the number of clear rounds. Ann. UMCS, 1: 251-257.

Viklund Å., Näs holm A., Strandberg E., Philips s o n J. (2011). Genetic trends for performance of Swedish Warmblood horses. Livest. Sci., 141: 113-122.

Wallin L., Strandberg E., Philips s on J. (2003). Genetic correlations between field test results of Swedish Warmblood Riding Horses as 4-year-olds and lifetime performance results in dressage and show jumping. Livest. Prod. Sci., 82: 61-71.

Wikström A., Viklund $\AA$., Näsholm A., Philipsson J. (2005). Genetic parameters for competition traits at different ages of Swedish riding horses. Proc. 56th Ann. Meet. of European Assoc. for Animal Prod., Uppsala, Sweden, 5-8.06.2005, pp. 5-8.

Received: 1 VII 2013

Accepted: 10 X 2013 